\title{
A reforma política no México: uma análise crítica dos avanços e retrocessos nas novas leis eleitorais do país
}

\author{
Alfonso Myers Gallardo
}

\section{Resumo}

O presente ensaio expõe o impacto da Reforma Político-Eleitoral de 2013 no México e tem como principal objetivo descrever os aspectos mais relevantes para o país e a sua democracia. A primeira parte do artigo apresenta uma breve abordagem histórica dos avanços e retrocessos realizados por meio das principais reformas eleitoras realizadas no país. Em seguida, analisam-se criticamente os pontos essenciais dessa nova reforma mexicana: a criação do Instituto Nacional Eleitoral (INE), as mudanças eleitorais relacionadas à reeleição, as questões referentes aos governos de coalizão, as candidaturas independentes, o financiamento e, por fim, o tema alusivo aos percentuais mínimos para registro dos partidos no México. A conclusão obtida por meio deste artigo é que a nova Reforma Político-Eleitoral mostra avanços e retrocessos; no entanto, segue sendo uma "obra em construção", já que os primeiros impactos deste conjunto de leis na democracia mexicana dependerão do panorama político do país e do resultado das eleições intermediárias que serão realizadas em 2015.

Palavras chaves: Reforma Eleitoral, Reeleição, Governos de Coalizão, Fiscalização, México.

\begin{abstract}
The present essay intents to expose the impacts of the 2013 Mexican political-electoral reform, describing its most relevant features. We make a historical briefly approach of the advances of the Mexican electoral reforms to analyze the essential points of the new reform: creation of the National Electoral Institute, re-election, coalition governments, independent candidates, financing and thresholds for registration. The new electoral political reform shows progress and setbacks, but is still a
\end{abstract}

\section{Sobre o autor}

Investigador na área de Ciência Política da Universidade de Salamanca, Espanha. Doutorando no programa de Estado de Direito e Governança Global da Universidade de Salamanca, Espanha. Mestrado em Democracia e Bom Governo pela Universidade de Salamanca, Espanha. Mestrado em Corrupção e Estado de Direito pela Universidade de Salamanca de Salamanca, Espanha. 
'work under construction' and their impacts on democracy depends on the political background of the country and the interim elections of 2015.

Key Words: Electoral Reform, Re-election, Coalition governments, Financing, Mexico.

Artigo recebido em I de agosto de 20I4. Aceito para publicação em 9 de outubro de 2014 .

\section{Considerações prévias}

O México é um país democrático com sistema presidencialista no qual o presidente, Enrique Peña Nieto, do Partido Revolucionário Institucional (PRI) é o chefe de Estado e também chefe de Governo. Os poderes da União no México são três: Executivo (Presidente), Legislativo (formado pela Câmara dos Deputados e de Senadores) e Judiciário (formado pela Suprema Corte de Justiça da Nação, Conselho da "Judicatura" Federal, que seria o órgão responsável pela administração do Poder Judiciário da Federação e pelos Tribunais Colegiados e de Circuito e Juizados de Distrito). O México é formado por 31 Estados e um Distrito Federal (Cidade do México). Cada um desses Estados e o Distrito Federal possuem três poderes: Executivo (formado pela figura do Governador do Estado), Legislativo (Congresso Unicameral) e Judiciário (Tribunais estaduais).

No México, o sistema eleitoral é misto. Ou seja: os votantes elegem os seus representantes (Legislativo) por meio de dois sistemas: um é o de representação proporcional, e o outro seria por meio de maioria relativa com listas fechadas e bloqueadas (não necessitaria ter o 50+1). É importante lembrar ainda que, no México, em nenhum momento existe a possibilidade de segundo turno, já que as eleições são definidas sempre no primeiro turno. No entanto, a duração do mandato presidencial é de seis anos, sem direito à reeleição, assim como o mandato de senadores, que também tem a duração de seis anos. Não obstante, o mandato de Deputados Federais, Estaduais e de Prefeitos tem uma duração de apenas três anos.

As eleições gerais são celebradas para eleição do Presidente da República; no entanto, as eleições para os cargos legislativos federais e as eleições intermediárias tanto para prefeito quanto para deputados estaduais são realizadas três anos após as eleições presidenciais, com a renovação tanto dos cargos legislativos estaduais quanto da renovação dos deputados federais. Em nível federal são eleitos 300 deputados de forma direta e 200 deputados de maneira 
proporcional. Já para o Senado, são eleitos três senadores por cada unidade federativa e 32 por representação proporcional, totalizando 128 senadores. Até 2000, o México possuía um sistema de partidos hegemônico, mas atualmente é formado por um multipartidarismo, com a representação do Partido Revolucionário Institucional (PRI), Partido da Ação Nacional (PAN) e o Partido da Revolução Democrática (PRD).

\section{Introdução}

Dentro da ontologia do direito eleitoral, está bastante claro o objetivo de conservar, promover e proteger a democracia, convertendo-a em uma ciência dinâmica e de evolução constante (Nohlen, 1999, p. 391). A aplicação do Direito Eleitoral depende, entre outras coisas, da harmonia dos representantes legislativos que em sua máxima expressão têm como objetivo a criação, a melhora e o aperfeiçoamento de Constituições, Leis e Regulamentos, com a finalidade de aprimorar o sistema eleitoral em benefício da preservação da Democracia. No entanto, quando uma normativa encontra-se ultrapassada pela realidade cotidiana das atividades político-eleitorais, nasce a necessidade imensurável de transformação dessas normas para que se adequem ao contexto, às necessidades e às exigências atuais.

O objetivo geral deste artigo é fazer uma breve revisão e balanço descritivo das reformas eleitorais no México através de um olhar geral que retoma as reformas mais relevantes, a criação do Instituto Federal Eleitoral (IFE), suas consequências e impactos durante a década de 90 e os anos 2000. O objetivo específico é analisar a reforma político-eleitoral de 2013, bem como os seus aspectos essenciais, alcances e polêmicas, buscando identificar as principais tendências dessa reforma e os pontos importantes que se encontram em debate político no México por meio de análises dos diversos aspectos dessa nova lei.

O presente artigo trata de analisar, com um enfoque mais acadêmico, analítico e menos opinativo o caráter inovador do escopo que a Reforma Político-Eleitoral de 2013 ainda está por definir. Atualmente, das poucas análises existentes, poucas são as que contribuem ao corpo da literatura fora do contexto mexicano, o que permite ao público exterior ter uma noção dos acontecimentos políticos e eleitorais que estão acontecendo no México neste momento. 
Por isso, este artigo cumprirá com o propósito de situar o leitor a respeito das ações jurídicas eleitorais mexicanas, que englobam o cidadão e as instituições que nelas se baseiam, mensurando aspectos positivos e negativos.

\section{Métodos}

$\mathrm{Na}$ primeira parte do ensaio se faz uma abordagem histórica com a finalidade de descrever, de forma abstrata, as reformas eleitorais no México, para então poder explicar quais foram as suas consequências e os seus impactos mais profundos na vida política mexicana. A perspectiva deste estudo não é fazer uma comparação entre o antes e o depois da reforma, mas sim uma apreciação dos elementos envolvidos nesses dois momentos; logo, a análise será diacrônica, pois supõe uma referência que compara os elementos históricos mais relevantes de maneira cronológica. A segunda parte do ensaio, que corresponde à Reforma Político-Eleitoral 2013, corresponde a uma análise do marco jurídico do direito eleitoral pelas bases constitucionais e legais, desde um enfoque positivista, descrevendo os conteúdos e aspectos jurídicos da Reforma, para, posteriormente, analisá-la no marco da interpretação e aplicação, tanto do cidadão mexicano como das instituições eleitorais no país, mostrando os avanços e retrocessos que ainda existem no México.

\section{Retrospectiva histórica: Períodos de reforma}

\section{I Primeiras leis eleitorais de ordem constitucional}

Desde a promulgação da Constituição Política do México, no dia 5 de fevereiro de 1917, o México tem vivido uma série de mudanças notáveis no âmbito eleitoral, tais como a criação das Juntas Eleitorais para organização e qualificação das eleições presidenciais e legislativas, embora sem uma norma especial que regularizasse tais processos. Em 1946 se promulga a Lei Federal Eleitoral e se torna a primeira medida para a regulamentação dos processos eleitorais e para a normatização da criação dos Partidos Políticos. No dia 04 de dezembro de 1951, uma nova Lei Eleitoral Federal regula a convocação das eleições, trazendo consigo uma mudança importante para a competência eleitoral, que são os meios de defesa em casos 
de irregularidades do processo eleitoral. Em 1973, surge uma nova Lei Federal Eleitoral que se converte em uma importante reforma em matéria de administração de eleições, partidos políticos e justiça eleitoral.

\subsection{Reforma Política de 1977}

Nesta época existia uma sobre representação do Partido Revolucionário Institucional (PRI), motivo pelo qual surge a Reforma Política de 1977, que introduz a Lei Federal de Organizações Políticas e Processos Eleitorais, que regulou os ingressos, o registro de coligações e candidaturas dos Partidos Políticos na arena política, introduzindo a representação proporcional. Essa Reforma se converte na resposta estatal frente à realidade conflitiva crescente e expansiva que embarcava o contexto mexicano daquela década e que, ademais de tudo isso, gerou uma abertura política importante (Woldenberg 1990, p. 27).

Neste período, uma grande mudança política é desencadeada no México, já que se estabelece na Constituição o reconhecimento de certos elementos dos partidos que os permitiram adquirir competência e obtenção do voto popular, como o apoio em tarefas editoriais e de propaganda política, mesmo que com esta prática houvesse alguns benefícios dentro da lei que careciam de uma regulação efetiva (Córdova, 2011, p. 352).

\subsection{Reformas nos anos 80}

Em 1986 são introduzidas as mudanças legais que regulamentam o financiamento estatal aos partidos político e, desta maneira, os partidos de oposição do tipo Non Incumbent New e Non Incumbent Never (Myers-Gallardo e Fajuri, 2013, p. 145) passam a construir estratégias e chegam mais fortes do que nunca às eleições de 1988, já que, por norma, com a criação do Código Federal Eleitoral neste mesmo ano, os deputados por representação proporcional passaram de 100 a 200. Esse aumento tinha como objetivo evitar a "pulverização" do espectro político e limitar o acesso dos partidos políticos à arena eleitoral com a eliminação do registro condicionado e das associações políticas, fortalecendo a maioria na Câmara dos Deputados através do "cadeado", ou seja, do fortalecimento da 
governabilidade (García, 2011, p. 81). Em 1989 são determinados os tipos de financiamento público: a) por atividade eleitoral, com base no número de votos obtidos pelas eleições de deputados e senadores; b) por atividades gerais $(10 \%$ do conceito anterior, outorgado de maneira igualitária); c) por substituição (o Estado entregava aos partidos políticos o equivalente a $50 \%$ dos salários dos seus respectivos legisladores) e d) por atividades específicas (reembolso de até 50\% dos gastos realizados em atividades de capacitação, investigação e difusão da cultura democrática).

\section{Criação do Instituto Federal Eleitoral (IFE)}

Passada várias reformas ao longo do século XX, é apenas nos anos 90, depois de muitas suspeitas de irregularidade e insatisfação dos partidos Non Incumbent, que surgiu, com a eleição de Carlos Salinas de Gortari em 1988, o IFE, em 11 de outubro de 1990, com autonomia técnica, ainda que dependente do governo (Azis, 1999, p. 321). A criação do IFE foi uma das mudanças de maior importância na arquitetura eleitoral em México. O IFE deu validez e legitimidade às eleições federais, tanto de Deputados e Senadores, como de Presidente da República desde 1994. É a partir da criação desse órgão que a oposição começa a participar da edificação da vida democrática, gerando com isso derrotas eleitorais ao PRI, especialmente em governos estaduais, e a presença da oposição em importantes partes do país (Myers-Gallardo, $2012)^{1}$. O IFE se encontra fundamentado por meio do artículo 41, fração V da Constituição Federal, onde poder ser encontrado sua estrutura e a definição de sua independência. Com as reformas de 1994 e 1996, o IFE é convertido em um organismo público autônomo, com personalidade e patrimônio próprio, em cuja integração participa o Poder Legislativo da União, os partidos políticos nacionais e os cidadãos, sempre baixo os princípios de certeza, legalidade, independência, imparcialidade e objetividade (Elizondo, 2012, p. 13).

1. Em 1997, nas eleições que renovaram parte do poder legislativo mexicano, pela primeira vez na história do PRI, o partido não obtém a maioria absoluta no Congresso. 


\section{I Consequências da criação do IFE}

As consequências da criação do IFE e das reformas posteriores a sua criação passam a render ao Instituto uma infinidade de tarefas (García, 2011, p. 87). Entretanto, assim que a representação proporcional já tinha se consolidado como uma Instituição que impulsionava e assegurava a estabilidade do sistema de partidos mexicano, teve início um processo onde as condições eram cada vez mais justas para a competência eleitoral. Ou seja: o foco passou a ser os esforços relacionados à questão da transparência e da veracidade do sufrágio. Rumo às eleições intermediárias de 1997 e as presidenciais do ano 2000, dentro das duas Câmaras, tanto o PAN quanto o PRD contaram com maior força para completar esse ciclo de reformas e consequentemente ganharam mais espaço na cena política mexicana (Farías, 1995, p. 85).

Esses câmbios institucionais, conjugados com o financiamento público, foram chaves para a transição política no México. A prevalência do financiamento público sobre o privado garantiu uma competência equilibrada e não um ritual com ganhadores e perdedores predeterminados. Dentro desse contexto, era perceptível o alto grau de insatisfação da sociedade e a existência de reações anti-sistêmicas na dimensão dos partidos Non Incumbent derrotados constantemente (Myers-Gallardo 2012, p. 102)2. Partindo destes acontecimentos, se observa que as principais consequências foram: a aparição de referentes eleitorais e o surgimento de um debate parlamentário marcado pela pluralidade de ideias, que culmina em uma resposta imediata nas urnas com as derrotas do PRI por todo o país, sendo a mais importante e definitiva no ano de 2000, quando o candidato do PAN Vicente Fox consegue derrotar pela primeira vez os priistas no Executivo Federal, constituindo desta maneira a transição do até então poder político hegemônico, ao multipartidarismo.

Passada a grande derrota do PRI, foram poucas as mudanças sofridas pelo IFE. A vitória do PAN mostrou que o México estava vivendo um ambiente mais democrático e com maior credibilidade à

2. Em uma retrospectiva, podemos observar que nas eleições de 1976 apenas um candidato concorreu à presidência da República (José López Portillo). Já em 1982, 7 concorrem à eleição, com a vitória de Miguel de la Madrid Hurtado; e, em 1988, as eleições mexicanas tiveram uma concorrência, para o executivo federal, até então incomparável. 
autoridade eleitoral. No entanto, a falta de uma reforma significativa entre os anos de 2000 e 2006 faz com que o Instituto deixe de ser renovado e, assim, em ótimas condições para se adiantar aos possíveis problemas que podiam ser apresentados, além de ter as condições ideais e as ferramentas necessárias para solucionar estas mesmas deficiências. No entanto, tanto o IFE quanto a maioria dos mexicanos não poderiam imaginar e muito menos esperar pelas dificuldades que estariam por enfrentar nas eleições de 2006, que depois se mostrariam tão problemáticas.

Em 2006, com a vitória bastante apertada de Felipe Calderón (PAN) sobre o candidato Andrés Manuel López Obrador (PRD), com uma diferença menor que $1 \%(0,56 \%)$ entre os dois, a população passa a se questionar sobre a legitimidade dessa eleição e sobre as más práticas eleitorais durante todo o período de campanha (Myers-Gallardo 2013, 65). Diante desse difícil cenário, sete grupos do parlamento mexicano anunciaram uma série de reformas entre os anos 2007 e 2008. Essas mudanças têm base em dois aspectos fundamentais: 1) Redução do gasto público sobre o privado e um novo sistema de cálculo onde somente ocorrem dois fatores: $65 \%$ do salário mínimo vigente da capital mexicana e o número de cidadãos inscritos no padrão eleitoral ${ }^{3}$ e 2 ) acesso aos partidos políticos e aos meios de comunicação social, dos quais consistiu acesso à rádio e à televisão como garantia constitucional (Art.41. B da Constituição Mexicana), onde o IFE seria obrigado a garantir e administrar esse direito, evitando, assim, que nenhuma pessoa física contratasse ou adquirisse os serviços de rádio e TV (Córdova, 2011, 362). Dessa maneira, o papel desempenhado pela legislação logrou facultar constitucionalmente ao IFE como o único órgão administrador de gastos de campanha e acesso aos meios de comunicação, evitando assim o financiamento indevido desses canais de comunicação aos partidos políticos ou a alguns candidatos (Carbonell, 2007, p. 115).

3. O financiamento para atividades dos partidos políticos resultava na multiplicação de ambos os fatores: $30 \%$ estavam distribuídos de maneira igualitária e $70 \%$ proporcionalmente à votação obtida por cada um destes partidos na última eleição de Deputados. Com esse resultado, calcula-se o financiamento para gastos de campanha (30\% quando apenas se elegem Deputados ou $50 \%$ quando se elegem Deputados e Senadores) e para atividades especificas 3\%. 
Depois dessas reformas, foram realizadas as eleições de 01 de julho de 2012, que representou uma data que definiria o mapa político-eleitoral mexicano, já que em 15 Estados foram renovados os cargos de prefeito, de Deputados estaduais e de Governadores. No âmbito federal, foram eleitos simultaneamente o presidente da República e os representantes à Câmara de Deputados e do Senado. Em relação ao executivo federal, e tomando em consideração que no México não existe segundo turno, a vitória priista foi contundente, já que o seu candidato obteve $38,21 \%$ dos votos contra $31,59 \%$ da aliança formada pelos partidos de esquerda (PRD) e $25,41 \%$ dos votos dos partidos de direita (PAN). Apesar de todo esse contexto, o processo eleitoral de 2012 teve situações bastante controversas. No que corresponde ao campo da justiça eleitoral, houve alguns "tropeços legais" que ganham ressalto no que diz respeito à análise e à sentença final realizada pelo Tribunal Eleitoral do Poder Judicial da Federação, além de outras grandes controvérsias e supostos casos de irregularidades e delitos eleitorais denunciados pelo Movimento Social "\#YoSoy132" 4 , assim como delitos de intimidação e hostilidade contra observadores eleitorais e cidadãos que denunciaram atos presumidamente ilícitos à cooptação, coesão, compra de votos e roubo de urnas (Corona, 2013, p. 34). Em poucas palavras, a eleição de 2012 no México não foi isenta de questionamentos por parte da sociedade e dos partidos políticos, o que culminou na inquietante necessidade de uma permanência constante na revisão legislativa que adequasse e aperfeiçoasse o sistema eleitoral no México.

\section{Reforma Político-Eleitoral 20I3:Aspectos essenciais}

Um dia depois da proclamação de Peña Nieto, no dia 02 de dezembro de 2012, se firma o "Pacto por México", que entre outras coisas, coloca em evidência diversos aspectos relacionados à matéria política e eleitoral. O "Pacto por México" marca o início de diversas

4. Este movimento social se auto define assim: "\#YoSoy132" é um movimento com base estudantil, que se articula por meio de oito princípios gerais que permitem vincular a direção e participação de todos os comitês e, por sua vez, contribuir para a construção da conscientização da cidadania". Ver: http://www.yosoy132media. org/ 
ações relacionadas aos partidos políticos e às eleições, tanto em tempos eleitorais quanto em tempos não eleitorais.

Depois que houve uma grande dinâmica na arena política mexicana, no dia 05 de dezembro de 2013, foi publicada na Gazeta Parlamentária da XLII Legislatura da Câmara de Deputados um projeto que reforma, adiciona e derroga diversas disposições da Constituição Federal em caráter político-eleitoral. Tal projeto foi remetido ao Senado e à Câmara de Deputados para discussão e votação. Mais tarde, no dia 10 de fevereiro de 2014, o projeto foi publicado no Diário Oficial da Federação, contemplando uma importante e grande variedade de instituições e temas bastante relevantes ao Estado mexicano e às entidades federativas e municípios, que a continuação será abordada.

\section{I Criação do Instituto Nacional Eleitoral (INE)}

Com a reforma constitucional, em caráter político-eleitoral, se redesenhou o regime eleitoral e se criou uma nova autoridade com abrangência nacional: o Instituto Nacional Eleitoral (INE), que tinha como principal objetivo homologar os padrões em processos federais e locais. Desta maneira, o INE se transforma na autoridade eleitoral máxima por excelência, com independência e profissionalismo e, ainda que com a sua criação sigam coexistindo órgãos eleitorais estaduais, o INE pode desapoderar atribuições desses órgãos, o que acaba por fortalecer esse novo Instituto muito mais que o IFE, extinto pós-criação do INE (Miranda, 2014, p. 19). Com a desaparição do IFE, a reforma reconfigurou a natureza e as funções do INE, somando-se 74 novas atribuições ( 53 de alcance nacional). No geral, a função básica do INE será a mesma que a do IFE no que se refere à administração das eleições federais. No entanto, se outorgam algumas outras funções a nível estadual ou local. O INE será uma autoridade supervisora, mas com capacidade de dar seguimentos ao desenvolvimento de diversos processos locais (Art. 41, V, apartado $\mathrm{B}$, incisos a e b). De maneira complementar, o INE poderá organizar, desenvolver, computadorizar e declarar resultados concretos de consultas ou pesquisas populares (Art. 35, fracción VIII.6) e fiscalizar os partidos federais ou estaduais (Art. 41, V, apartado B).

Com criação do INE, passam a atuar 11 magistrados, ao invés de nove, como era no antigo IFE; eles formam parte do Conselho 
Geral, um deles como presidente. Possuem uma duração no cargo de nove anos, sem direito à reeleição, e são selecionados por uma comissão integrada à Câmara de Deputados, à Comissão Nacional de Direitos Humanos e ao Instituto Federal de Acesso à Informação. Ao final dessa seleção, passam pela votação e eleição na Câmara de Deputados Federal, sendo eleitos pelo voto de dois terços dos membros presentes na Câmara (art. 41, base V, apartado A). Além disso, se cria um Serviço Profissional Eleitoral Nacional (SPEN) que será regulado pelo INE mediante algumas regras estabelecidas constitucionalmente e pelos regulamentos respectivos (Art.41, base $\mathrm{V}$, apartado D). Paralelo a este serviço, continua mantida a existência de institutos locais (OPLE), mas com algumas mudanças importantes nas suas funções, integrações e na nomeação. As OPLE passam a ser formadas por seis magistrados e um Conselheiro Presidente, designados ou removidos de sua função pelo mesmo INE (Art. 41, base $\mathrm{V}$, apartado $\mathrm{C})^{5}$.

Quanto à matéria legal, com base nas mudanças constitucionais, essa reforma estende novos corpos normativos, como por exemplo a substituição do Código Federal de Instituições e Procedimentos Eleitorais (COFIPE) com duas leis de caráter nacional: A Lei Geral de Instituições e Procedimentos Eleitorais (LEGIPE) e a Lei Geral de Partidos Políticos (LGPP). Além disso, também é criada a Lei Geral de Delitos Eleitorais.

Em relação aos procedimentos de sanção, o INE fica encarregado de investigar infrações ou violações às leis, especialmente nos meios de comunicação e propaganda, submetendo todas essas questões ao Tribunal Eleitoral do Poder Judiciário da Federação. Com essa nova atribuição, o INE poderá ordenar, suspender ou cancelar, de maneira imediata, as transmissões em rádio e televisão (Art. 41, base III,

5. Suas funções serão: realizar o reconhecimento e computação de votos, a declaração de validez e a permissão de constância aos candidatos ganhadores, a realização de procedimentos de consultas populares em âmbito local ou estadual; também serão encarregados de administrar o acesso das prerrogativas dos candidatos e partidos políticos, da realização de tarefas de natureza cívica, a preparação da jornada eleitoral, impressão de documentos e a produção de materiais eleitorais e, finalmente, dos resultados das preliminares. À parte de tudo isso, também serão responsáveis pelas pesquisas de opinião, pela observação eleitoral e pela contagem rápida de votos. Algumas das funções também se desenvolvem conforme o que for estabelecido pelo próprio INE (art. 41, base V, apartado C). 
apartado D). Por sua parte, o Conselho do INE terá novas faculdades que lhe permitem, com o voto de pelo menos oito conselheiros: delegar funções e atrair determinadas competências de acordo com cada função designada, o que pela própria transcendência pode criar certos critérios de interpretação (Art. 41, base V, Apartado C).

\section{I.I Crítica: aspectos positivos e negativos}

É importante ressaltar que, assim como se criticou o "Pacto por México", esse modelo tem como tendência a centralização do poder eleitoral, já que faz com que o INE possa interferir diretamente na atuação, função e até mesmo autonomia das OPLE. Essa centralização do INE tem como consequência direta a criação de um sistema nacional para a organização de todas as eleições no México (federais, estaduais e municipais), fazendo assim com que o INE tenha participação fundamental na função estatal de organizar eleições. Ou seja, de certa forma, volta-se à existência de um órgão altamente e amplamente centralizado ao presidencialismo, uma prática política que sempre foi tão rechaçada pelos partidos de oposição do PRI, que foram os mesmos que aprovaram a criação do INE (Alarcón 2013, p. 20). Por exemplo, o INE tem entre suas atribuições o direito a suspender ou cancelar de maneira imediata as transmissões em rádio e televisão ${ }^{6}$. O INE também é responsável por eleger os Conselheiros Estatais dos OPLE e, de maneira conjunta com eles, é responsável pela coordenação das eleições locais. No entanto, se o INE detecta, ou algum autor político denuncia, que na entidade federativa existe algum tipo de ingerência ou intromissão comprovada dos governos no Estado que afete, de maneira indevida, a organização do processo eleitoral, ou ainda se são geradas condições de inequidade, pode tirar a autonomia do OPLE no que diz respeito ao processo eleitoral e não tomar em consideração suas atribuições ${ }^{7}$. Em relação ao anterior, recebe o nome de "Assunção",

6. Art. 41, III, apartado D: “o Instituto poderá impor, entre outras medidas cautelares, a suspensão ou o cancelamento de maneira imediata as transmissões em rádio e televisão, em conformidade com o que disponha a Lei”.

7. Art. 41, base V, Apartado C: entre outras coisas incorporo textualmente: “... Assumir diretamente a realização das atividades próprias de função eleitoral que correspondam aos órgãos eleitorais locais... c) Trazer ao seu conhecimento 
se encontra no Art. 121 da LEGIPE e para que essa ação seja levada a cabo, se deve comprovar a violação dos princípios constitucionais de imparcialidade, certeza, legalidade, objetividade e equidade na contenda eleitoral, previstos por meio do Art. 41 da Constituição Mexicana.

Outro fator importante para analisar é que ainda que não se centralizem todas as tarefas do INE, elas seguem sendo excessivas, especialmente se levarmos em consideração que, por exemplo, em 2018 ocorrerão as eleições para eleger o Presidente da República, Senadores e Deputados Federais, bem como as eleições em mais de 15 Estados do país. Cada Estado elegerá o seu Governador, Deputados Estaduais e Prefeitos, o que pode saturar a capacidade de operação do INE e, consequentemente, causar um desempenho deficiente que pode levar os seus conselheiros a alcançar a ineficácia e incompetência devido à grande quantidade de processos eleitorais que tenham que ocorrer como resultado de suas novas atribuições de centralização. No entanto, essa questão não termina apenas aí, já que a função que o INE pode adquirir em relação às eleições locais, se levadas a cabo, acabam por estimular o conflito pré-eleitoral e a deslegitimar o OPL. Esta autonomia concedida ao INE pode ainda promover entre os partidos de oposição, ou ainda entre os que estiverem mal avaliados nas pesquisas eleitorais, uma busca dos mesmos ao órgão, para evitar que o partido Incumbent tente influenciar as eleições a favor do candidato oficial do governo.

O Conselho Geral do INE, ao ter a faculdade e função de designar e remover os Conselheiros do OPLE pode estimular e favorecer as constantes pressões para seleção, nomeação ou remoção de outros conselheiros. Além disso, o INE pode atrair um papel de negociação política que antes somente existia nos Estados, o que acabaria por gerar uma maior politização dentro do próprio Instituto. Por outro lado, não parece existir uma informação suficientemente forte para que o INE garanta, nos OPLE, funcionários mais aptos ou imparciais, já que dentro do próprio método de seleção os resultados podem ser bastante variados entre os Estados, por mais que, em regulamento, seja o mesmo. Ou seja: um candidato do Estado de Jalisco ou do Distrito Federal, com uma maior qualificação que um candidato

qualquer assunto de competência dos órgãos eleitorais locaos, quando sua transcendência assim o mereça para estabelecer um critério de interpretação...”. 
do Estado de Oaxaca ou Chiapas, pode acabar ficando de fora do processo de seleção. Em relação aos resultados, se observa que, entre as entidades com maior índice de desenvolvimento, a competência é ainda maior. Em síntese: não existe nenhuma homologação e muito menos meritocracia ${ }^{8}$.

\subsection{Eleição consecutiva em alguns cargos: $O$ fim de 80 anos de NÃO REELEIÇÃO}

O tema da reeleição legislativa mexicana tem precedentes desde a primeira Constituição Federal em 1824 (que segue o modelo da constituição dos Estados Unidos) e também esteve presente na Constituição de 1857. Como resultado dos governos autoritários do México durante o Século XIX, em que havia limites para reeleger-se, depois da Revolução Mexicana de 1910 e desde a promulgação da Constituição de 1917, o tema da reeleição sempre foi um tema impenetrável da política mexicana. Até essa Reforma de 2013 não existia reeleição no México em nenhum nível de governo. Em 1933, se legislou esse principio de não reeleição a fim de deixar de lado os governos de caudilhos e passar aos regimes de instituições.

Ou seja: tiveram que passar 80 anos de não reeleição para que este princípio fosse mudado. A Reforma contempla constitucionalmente (Art. 59) a reeleição de Deputados (estaduais e federais) e Senadores por até 12 anos. No caso dos deputados, poderiam ser reeleitos por até 3 vezes consecutivas depois do primeiro mandato, o que culminaria em um total de 4 mandatos, já que o seu mandato dura três anos e, no caso dos Senadores, apenas uma vez, já que o seu mandato dura seis anos. A reforma tem validade já para as próximas eleições de 2015 para o caso dos Deputados e para 2018 na votação para o Senado. Essa reeleição não entra em vigor para os parlamentares que já exercem e ocupam cargos na legislatura atual. É importante ressaltar ainda que para concorrer à reeleição, o candidato deve estar vinculado sempre ao mesmo partido ou coalizão partidária com a qual foi eleito. Esta mesma condição também é válida para os casos de candidaturas independentes. Essa regra foi estabelecida com o objetivo de evitar o que é

8. Acesso aos resultados: http://www.ine.mx/archivos2/portal/Estados/OPL/resultados/ (Acesso 30 de Julho de 2014). 
conhecido popularmente como "chapulines" " no México (Miranda 2014, p. 20).

\subsection{Críticas: aspectos positivos e negativos}

A reeleição incluída nessa Reforma quebra 80 anos de resistência ao tema. O PRI, ao largo de seus mandatos, sempre se negou a aceitar a reeleição. De uma maneira geral, ao menos em teoria, se supõe que a reeleição traga algumas vantagens como, por exemplo, a criação de vínculos estreitos com os eleitores, já que eles fariam com que os políticos se sentissem preocupados com a responsabilidade de "prestar contas" ao seu eleitorado. Isso, em tese, geraria a promoção da confiança entre representantes e representados, além da possibilidade de uma maior profissionalização e especialização dos políticos em seus cargos.

No entanto, deixa-se claro que o modelo de reeleição adotado não retoma a influência norte-americana devido ao condicionamento do político ao partido ou à coalizão aos quais foram eleitos (Dworak, 2003, p. 252). Ou seja: os políticos respondem aos seus partidos e representam a si mesmos e por isso, no pior dos casos, a reeleição dependerá muito mais das cúpulas partidárias, que representam esse candidato, que do voto do eleitor, já que se deve considerar que um legislador somente poderá ser reeleito, e quando o for, com o mesmo partido com o qual ganhou a sua primeira eleição ${ }^{10}$. Uma das maiores críticas a este modelo de reeleição é que não inclui a instauração da figura de "renovação de mandato", que seria uma medida de "pesos e contrapesos", que faria com que os cidadãos pudessem retificar os seus representantes não apenas através do voto, como também da qualificação do seu desempenho, ao qual, por uma grande parte, acaba por colocar em prova a cultura política do país (Zarkin, 2013) e, por sua vez, acaba também em não transformar importantes paradigmas da democracia no México ${ }^{11}$. A falta de renovação de

9. Em português, "Chapulines" seriam gafanhotos e é o termo usado no México para se referir aos políticos que pulam de partido em partido a fim de assegurar a continuação de seus mandatos.

10. A exceção é quando esse mesmo político renuncia antes de ter cumprido a metade de sua gestão (18 meses).

11. Neste sentido, o Latinobarómetro 2013, que é um excelente indicador da cultura política de diversos outros países, chama a atenção pelos seguintes dados referentes ao sistema político: no México, apenas $21 \%$ da população está satisfeita com 
mandato faz com que o cidadão perca no que diz respeito a falta de profissionalização política, já que em caso de que existam uma abundância de legisladores "amadores", os mesmos não poderão ser castigados. Isso levaria a inexistência de incentivos para que se cumpram as promessas de campanha.

Ainda no que se refere ao tema da profissionalização, esta reforma não deixa claro o tipo de profissionalização que será alcançado por meio dessa mudança. Por um lado, no âmbito referente aos Institutos Eleitorais, se integra o SPEN, que em observância ao novo artigo 41 da Constituição Federal,

Art. 41. Compreende a seleção, ingresso, capacitação, profissionalização, promoção, permanência e disciplina dos servidores públicos dos órgãos executivos e técnicos do INE e do OPLE das entidades federativas, que são as que respondem ao aspecto eleitoral.

No entanto, essa disposição constitucional, refere-se apenas à questão profissional relacionada aos servidores públicos e ao desenvolvimento eficiente de suas capacidades. Já no que diz respeito aos legisladores, o tema da profissionalização está associado apenas ao âmbito temporal; ou seja, pela lei quanto mais tempo durar um deputado no poder mais profissional e melhor capacitado ele estará. A reforma não contemplou fatores importantes como os requisitos referentes à escolaridade ${ }^{12}$. É importante ressaltar que um bom político não é formado apenas pelo diploma que possui; mas, como variável, a formação acadêmica de um parlamentar deveria ser uma condição a ser incentivada, mesmo que esteja bastante claro que a eficácia do poder legislativo não é um tema acadêmico e sim de responsabilidade política. Não obstante, a reclamação popular gira

a democracia; $37 \%$ opina que poderia viver, tanto em um sistema democrático quanto em um sistema autoritário. Apenas 37\% considera preferir a democracia a qualquer outro tipo de governo ou regime político.

12. Atualmente, de acordo com os dados da Câmara de Deputados e do Senado da República, na atual Legislatura LVII (2012-2015), composta por 628 representantes (500 Deputados Federais e 128 Senadores), apenas 27 parlamentares possuem Doutorado, 136 têm Mestrado, 385 possuem apenas uma Licenciatura, 17 têm algum tipo de estudo técnico e 63 parlamentares possuem estudos menores a uma preparatória. Pode ser visto em: http://www.adnpolitico.com/legisladores (Último acesso no dia 21 de Julho de 2014). 
em torno da preparação dos seus representantes, inclusive com a satanização deste tema e a comparação entre a figura de Calígula e de importantes atores políticos mexicanos: "México, a nação mais corrompida que se viu na humanidade desde a época em que Calígula nomeou um cavalo para exercer o papel de cônsul" (Ayala, p. 1976).

Ao tratar do tema de profissionalização, essa reforma fala apenas no sentido do tempo adquirido por cada parlamentar em seu posto e, portanto, acaba relacionando a experiência legislativa com a chegada e o tempo permanecido no poder. A pergunta central passa a ser, então, a seguinte: a introdução da figura da reeleição passa a beneficiar os partidos ou os cidadãos? Nessa conjuntura, é importante entender a reeleição como uma oportunidade de prestação de contas, onde os eleitores podem castigar ou premiar os políticos; e, se eles querem ganhar, devem respeitar os desejos dos seus eleitores, e não dos seus partidos. Seguindo esta lógica, a reeleição se converteria em um poderoso instrumento, não apenas pelo incentivo na procura de uma maior profissionalização por parte dos políticos, mas sim pelo cumprimento dos parlamentares no que se refere ao trabalho legislativo e às promessas feitas durante campanha, porque teriam também um maior prazo de tempo para cumprir os seus compromissos. Isso, sem dúvida, fortaleceria a democracia.

No entanto, a situação no México indica que a reeleição é uma máscara que pouco se move do status quo, já que seus representantes, na prática, respondem muito mais aos interesses do partido que aos interesses e julgamento da sociedade. Nesse sentido, é relevante explicar que, para que se possa existir a reeleição, o candidato deve primeiro convencer o partido e, se não o convencer, enfrenta o efeito de "temporariedade fixa" prevista por meio do artigo 59 da Constituição mexicana ${ }^{13}$ sobre a renúncia de sua candidatura, que seria equivalente aos 18 meses no cargo, para que dessa forma possa garantir uma nova candidatura em

13. O artigo 59 da Constituição assinala: "Os senadores podem ser eleitos até dois períodos consecutivos e os Deputados ao Congresso da União até quatro períodos consecutivos. Essa postulação somente poderá ser realizada por este mesmo partido ou por qualquer partido da coalizão ao qual pertença o partido, com exceção dos que hão renunciado ou perdido a sua militância antes da metade do seu mandato". 
outro partido político. Esse mecanismo coloca em dúvida, não apenas a credibilidade do partido, como a própria credibilidade desse político. Além disso, quando passa a levar em consideração apenas os interesses do partido, o parlamentar acaba não deixando claro a quem representa e nem a quem o eleitor deve cobrar a prestação de contas, se é a ele ou ao seu partido (Przeworski et al., 1999).

Outro ponto bastante negativo é que a reeleição no México, especialmente a de Deputados Federais, pode acabar gerando um "questionamento nocivo das elites no poder" e, principalmente, um impedimento no sentido da renovação dessas mesmas elites (De Andrea, 2002). Em relação à renovação, me refiro ao sentido de que, pela lei, não foi anulada a opção de que um parlamentar possa mudar de um cargo para outro. Ou seja: no pior dos casos, um Deputado Federal poderia estar no poder por 12 anos, depois poderia candidatar-se ao Senado por mais 12 anos e novamente regressar à Câmara dos Deputados por mais outros 12 anos. Com isso, poderia facilmente permanecer no Poder Legislativo por até 36 anos, sem problema algum e saltando de um cargo parlamentar a outro de acordo com os seus interesses. Agora, com esta reforma, faz isso de uma maneira completamente legal e institucionalizada, ou seja, a reforma acaba mantendo os mesmos "chapulines", que supostamente busca eliminar.

\subsection{A nova "Cláusula de Barreira" e candidaturas independentes}

Outro ponto da reforma político-eleitoral do México foi o incremento do percentual mínimo necessário para que os partidos conservem seu registro. Dessa maneira, se reformam os artigos 41, fração I, e 54, fração II, da Constituição Federal, que tratam sobre a famosa "Cláusula de Barreira". Este aumento tem como objetivo impedir a obtenção ou conservação do registro de partidos que padecem de possuir uma verdadeira representatividade (Miranda, 2014, p. 19). Nesse sentido, se prevê que com o aumento, que passa de $2 \%$ a $3 \%$ como mínimo da votação total emitida, a fragmentação da representatividade no sistema pode ser evitada.

A nova reforma contempla um tema bastante controverso na história eleitoral mexicana: os candidatos independentes (Becerra 
e Miranda, 2010, p. 96-108) ${ }^{14}$. Instaura-se por meio da LEGIPE, que estabelece e determina os direitos e obrigações desses mesmos candidatos. Essa forma, caso queiram concorrer à eleição como Presidente, esses candidatos devem reunir assinaturas de ao menos $1 \%$ da lista nominal de todos os eleitores mexicanos. Já para os cargos de Senadores e Deputados, o número passa a ser $2 \%$ de todas as assinaturas nominais da entidade ou do distrito eleitoral. O principal objetivo, da inserção desse tipo de candidatura, é proporcionar a abertura de novos canais de participação, onde os cidadãos sem partidos possam ser eleitos em condições de igualdade e sem restrições indevidas.

\subsection{Crítica: aspectos positivos e negativos}

O tema referente à Cláusula de Barreira dos partidos é bastante difícil de ser analisado porque o seu futuro ainda é muito incerto. No entanto, há uma compreensão de que o cidadão comum também esteja de acordo com essa mesma mudança e com o acréscimo desse percentual mínimo ${ }^{15}$. Por outro lado, também existe uma crítica por parte da população especialmente no que diz respeito ao tema das candidaturas independentes contem-

14. O tema gera muitas controvérsias no México, já que depois da tentativa da candidatura independe do ex-chanceler da Secretaria de Relações Exteriores do México, Jorge Castañeda Gutman, para a eleição presidencial de 2006, pela primeira vez na história do país, a Corte Interamericana de Direitos Humanos condenou o México de forma vinculante a cumprir com ações que desde 2008 eram realizadas por meio de operadores jurídicos e que inclusive foram alvo e motivação de diversas reformas constitucionais, adequação de normas secundárias e critérios de jurisdição nacional, incluindo a Suprema Corte de Justiça da Nação. Ou seja: a partir do caso Castañeda vs. México, se criou um paradigma constitucional de direitos, onde as competências legislativas e de jurisdição não se limitam aos âmbitos territoriais dos Estados do Continente Americano. Dessa forma, este caso abre um consentimento e exceção à criação de fontes normativas supranacionais que outorgam competências jurisdicionais a órgãos de garantia internacional, como o Sistema Interamericano de Direitos Humanos, que deriva da Convenção Americana de Direitos Humanos e que, por sua vez, inclui o México.

15. Uma pesquisa realizada, antes do início de todos os ciclos da Reforma Eleitoral no México, apontou que $62 \%$ dos cidadãos se manifestaram de maneira favorável a aumentar o mínimo de $2 \%$ para $4 \%$, e apenas $16 \%$ foram contrários ao aumento deste percentual Pode ser visto em: http://www.parametria.com.mx/ carta_parametrica.php?cp=4603 (Acesso 21 de Julho de 2014). 
pladas pela reforma e ao limite estabelecido para registro dos partidos. De acordo com estes cidadãos, quanto menor o percentual estabelecido, maior seria o ganho do sistema de partidos no que diz respeito a pluralidade social e política do país. Em suma: ainda que a intenção seja limitar a autonomia do voto, isso seria completamente inadequado porque acaba limitando a representação das minorias em demérito do pluralismo. $\mathrm{O}$ aumento desse percentual mínimo pode também ter impactos mais sérios, principalmente nas entidades federativas do país, já que o multipartidarismo que se observa no âmbito federal não é o mesmo que existe em âmbitos mais locais. Por exemplo, o PRD pode ser afetado por essa medida do aumento deste percentual mínimo para registro dos partidos em mais de 10 Estados. Além disso, poderia fomentar ainda mais o bipartidarismo entre o PRI e o PAN, o que acabaria por promover o desaparecimento de uma alternativa esquerdista no México. Para entender melhor as críticas referentes ao percentual mínimo para registro dos partidos, basta contemplar os resultados da eleição presidencial de 2012, onde apenas o PRI, PAN e o PRD lograram ultrapassar os $3 \%$. Entretanto, o problema surgiria nas eleições intermediárias, que elegem os Deputados Federais, já que nessas eleições há uma menor participação eleitoral, com a existência de muitos partidos que não logram ultrapassar esse percentual.

Em relação ao tema das candidaturas independentes, ainda que se reconheça em todos os níveis de governo que a essas candidaturas serão outorgados financiamento público e concessão de tempo em rádio e TV, a crítica a essa questão é que, na prática, os seus requisitos são bastante complicados. A respeito disso é importante, ainda, levar em consideração a grande soma de votos que devem ser reunidos para o registro dos candidatos por meio dessas candidaturas e também a dificuldade de conseguir essa soma de votos sem nenhuma utilização de recursos públicos, já que os candidatos apenas poderiam ter acesso a algum tipo de recurso público, uma vez que já tenham sua candidatura registrada.

Por exemplo, no caso de querer concorrer à presidência da República, o candidato seria obrigado a recolher a assinatura de pelo menos $1 \%$ de todo o eleitorado nacional (quase $800 \mathrm{mil}$ pessoas) em um prazo de quatro meses. Tal medida, por si só, já 
estaria destinada a fracassar, já que um candidato independente não terá os meios e nem os recursos para efetivar tal ação.

\section{Outros aspectos de relevância e glossário de mudanças}

\section{I Financiamento e Gastos de campanha}

Existe uma crescente onda de demandas sociais opostas ao alto preço da manutenção do sistema democrático no México, especialmente quando comparado a outras necessidades tão importantes como saúde, educação, moradia e desenvolvimento humano. Ainda que tenham seus matizes, um dos fatores que determina o resultado eleitoral atual do país é a disponibilidade dos recursos econômicos ao qual pode contar um candidato. Ou seja: "Se possui mais dinheiro é possível ter maiores probabilidades de ganhar uma eleição" (Carbonell, 2007, p. 107).

É certo também que o financiamento público, estabelecido com base em um esquema proporcionalmente definido, seria uma maneira de dar equilíbrio à competência eleitoral e de evitar o uso de dinheiro ilegal, o financiamento paralelo das campanhas e o surgimento de graves problemas, como o da lavagem de dinheiro, que pode trazer consequências futuras com casos de corrupção e tráfico de influência. Com base nessas observações, o INE considerou importante aumentar o financiamento privado dos partidos políticos nacionais e locais, que agora sobe de $2 \%$ para $3 \%$. O INE terá ainda a responsabilidade e competência para fiscalizar as pré-campanhas e as campanhas de todos os partidos políticos nacionais e locais (novamente atua de maneira centralizada). Para que isto seja viável, o INE promete desenvolver um sistema informático que permita a concentração de informações dos faturamentos e das despesas dos partidos e de seus candidatos a nível nacional. Chama a atenção o fato de que, se um candidato ultrapassar os limites dos gastos da campanha, isso pode levar o órgão a anular a eleição. É importante observar que as regras para anulação estabelecem os seguintes preceitos: i) Excesso de gasto de campanha em 5\% ou mais do total autorizado; ii) Compra ou aquisição de cobertura informativa em rádio ou televisão; iii) Recibo ou a utilização de recursos de procedência ilícita ou o uso de recursos públicos nas campanhas. 
No entanto, para que a anulação seja outorgada, qualquer um dos itens acima mencionados tem que ser determinante no resultado da eleição; ou seja, se o candidato ganhar por uma margem muito pequena de votos, as regras para anulação se aplicam, mas, se a diferença do resultado entre o candidato ganhador e o segundo colocado forem muito grandes, mesmo que tenha sido cometida alguma das infrações, essa regra referente à anulação de votos não se aplicaria porque o resultado desses votos, assim como o ganhador, não seria alterado. Por outra parte, em caso de que seja provado que alguma regra referente à anulação de votos foi violada e que a violação dessa regra tenha sido determinante para o resultado eleitoral final, uma nova eleição extraordinária seria convocada, mas sem a participação do candidato responsável pela infração a essas mesmas regras.

\subsection{Espaços de rádio e televisão}

As democracias contemporâneas atuais têm como pilar de sustentação os meios de comunicação. É importante recordar a influência definitiva da mídia em processos eleitorais como os de 2006, no México, que teve um resultado nas urnas extremamente justo. Em geral, a influência desse fato pode ser tanto positiva quanto negativa; isto é, os meios de comunicação podem atuar devido à preferência de discurso de algum partido ou candidato, dependendo sempre da politização deste meio de comunicação e da organização corporativa ou comercial que lhe representa. Pela importância desse setor, a nova reforma incrementa em $60 \%$ o tempo destinado aos partidos políticos nacionais em rádio e televisão durante as pré-campanhas, com tempos determinados para períodos entre as campanhas intermediárias e, mais adiante, com tempos igualados aos partidos políticos nacionais e locais. Eliminam-se definitivamente as propagandas de 5 minutos e as de 20 segundos, além de todos os informes passarem a ser de 30 segundos. Com o objetivo de proporcionar inclusão e legitimidade, a contratação e distribuição de espaços de rádio e televisão contam ainda com a inserção de candidatos independentes. Esse fator foi bastante importante nessa reforma, já que contempla não apenas os partidos políticos nacionais e locais, mas também o direito dos candidatos independentes em usarem os meios de comunicação de maneira mais permanente e igualitária.

Dessa maneira, e devido a essa grande importância, o pluralismo midiático passa a ser a grande resposta ao fomento da diversidade de ideias que são transmitidas por meio do debate público e político da 
sociedade nas democracias modernas. Contudo, esta é uma questão tão crucial que não está relacionada de maneira exclusiva ao tema das reformas eleitorais, mas que também possui referência direta à possibilidade de aumento na concorrência por maiores fontes de informação, além de propiciar a formação de uma opinião pública mais livre e do acesso à informação a um maior número de pessoas (Bastida, 2003).

Com a reforma, os partidos políticos nacionais e locais, terão direito a um tempo de 30 minutos diários de rádio e televisão durante a pré-campanha, 24 minutos no período entre as campanhas intermediárias e 41 minutos diárias durante as campanhas. Também se amplia a obrigatoriedade de transmissão das propagandas dos partidos políticos e das autoridades eleitas, assim como a suspensão da propaganda do governo durante as campanhas políticas. Dentro dessa conjuntura, há ainda uma proposta bastante radical que tem como alternativa a proibição total da publicidade eleitoral em meios eletrônicos. Os defensores dessa proposta alegam que os partidos políticos devem aprender a viver sem o direito a compra desses tipos de espaços e a ganhar os votos com discursos e propostas interessantes, já que o que os cidadãos querem são ideias, e não canções ou slogans (Carbonell, 2007, p. 114).

\subsection{Governos de coalizão}

Em relação às coalizões entre os partidos, essa reforma eleitoral estabelece que o presidente eleito nas próximas eleições de 2018 terá a possibilidade de governar em um modelo de aliança com outras forças políticas ${ }^{16}$. Desta maneira, está previsto por esta reforma que o presidente eleito estabeleça um governo de coalizão com um ou vários partidos com representatividade no Congresso (Art. 74, III; Art. 76, II e XIII, Art. 89, fracción XVII; Art. 102, apartado A, fracciones II e III, da Constituição mexicana). Nesse aspecto, a lei acaba por estabelecer diferenças entre os tipos de coalizões que

16. Por meio deste acordo, o Senado terá que ratificar os integrantes do gabinete do Presidente da República, com exceção apenas dos titulares da Defesa e da Marinha. Em caso do governo preferir não fazer alianças com outros partidos, a Câmara dos Deputados teria que ratificar o Ministro de Fazenda, e caberia ao Senado ratificar a escolha do Ministro de Relações Exteriores. 
podem ser compostos por meio dessa reforma. São os seguintes: Coalizão total: partidos com o objetivo de postular todos os seus candidatos em um mesmo processo eleitoral federal ou local sob a mesma plataforma eleitoral; Coalizão parcial: postular ao menos $50 \%$ das candidaturas em um mesmo processo eleitoral sob uma mesma plataforma eleitoral; Coalizão flexivel: postular ao menos $25 \%$ das candidaturas em um mesmo processo e sob uma mesma plataforma eleitoral.

Dentro desse cenário, é necessário ressaltar algumas observações importantes. No sistema político mexicano, desde a sua primeira Constituição em 1824, foi adotado o presidencialismo como sistema de governo, que tem por sua característica principal e essencial a preeminência do Executivo sobre o Legislativo. Entretanto, os chamados "Governos de Coalizão", que tem origem nos sistemas parlamentários, são os que resultam das alianças no parlamento com a finalidade de formar um governo estável, com a particularidade de que este governo, resultado destas mesmas coalizões, subsista até quando essa aliança for mantida, já que com o seu término existe a possibilidade de que o governo seja dissolvido e de que outro, com novos "pesos e contrapesos", seja formalizado ${ }^{17}$. Esse mesmo modelo de alianças, levado ao âmbito exclusivamente mexicano, sob nenhuma circunstância teria possibilidades de se suceder, o que significa que as coalizões parlamentárias, conhecidas como Governos de Coalizão, da maneira como foram postuladas no México com a nova reforma eleitoral tem relação e pertencem mais a outra estrutura, a de um regime parlamentário, e não um regime presidencialista. Por isso mesmo, as críticas em relação a este aspecto específico, levando-se em consideração todo esse conceito com relação aos tipos de coalizões estabelecidas pela Reforma Política, ganham força porque não se encontram incluídas dentro da definição do que verdadeiramente deveriam ser os Governos de Coalizão, em términos mais teóricos.

Podemos analisar ainda todas essas questões com base simplesmente na definição clássica de presidencialismo feita por Giovanni Sartori (2003, p. 99): "um sistema político é presidencial se, e somente se, o seu Chefe de Estado: a) for eleito popularmente; b) não puder ser despedido do cargo por meio de uma votação do

17. O parlamento dissolve o governo, os integrantes renunciam e o Primeiro-Ministro ou Chefe de Governo é demitido. 
Congresso ou parlamento e; c) se esse mesmo chefe for a cabeça e a direção do seu governo". O que significa que não deveria existir, em um sistema presidencialista, a mesma flexibilidade que em um regime parlamentário, como bem definiu Juan Linz (Mainwaring e Shuggart, 1997). Analisando a argumentação anterior como algo sine qua non do sistema presidencial, é importante destacar que a renovação do Executivo por parte do Parlamento não é uma condição que se cumpre no México. Por isso mesmo, ao observar como se desenvolveu o debate no Congresso mexicano e a forma como foi construída essa parte específica da reforma, percebe-se que o tema referente às coalizões se trata de uma necessidade de se trabalhar de forma conjunta, tanto o Congresso quanto o Executivo, a aprovação de reformas constitucionais e leis que exigem o estabelecimento de maiorias qualificadas, evitando assim uma paralisação legislativa como a que sucedeu durante os governos presidenciais do PAN de Vicente Fox e Felipe Calderón; ou seja: uma forma regulamentar na qual o que se conhece como uma aliança para competir apenas durante as eleições acaba por se converter em uma coalizão que perdura, mesmo que as eleições tenham passado.

\subsection{Paridade de gênero}

A Reforma Eleitoral no México deu um passo bem grande, no que diz respeito à paridade de gênero, estabelecendo constitucionalmente (Art. 41.I) que as candidaturas, tanto na Câmara de Deputados como no Senado, devem ser ocupadas de maneira igualitária por homens e mulheres $(50 \%$ a $50 \%)$. Desta maneira, a reforma obriga aos partidos políticos a promoção e garantia da paridade de gênero e postulação igualitária de candidatos a cargos de eleição popular no Poder Legislativo. Outra novidade interessante dessa nova regra é que, com essa reforma, tanto os candidatos registrados quanto os seus suplentes devem ter o mesmo gênero. Com essa nova reforma aprovada por maioria absoluta no Senado, $50 \%$ das novas candidaturas, tanto em nível federal quanto em nível municipal, devem ser reservadas às mulheres, o que também será um desafio a ser enfrentado já para as próximas eleições de 2015, pois atualmente apenas 37\% da Câmara dos Deputados e 33\% do Senado é composto por mulheres. É importante destacar que essa reforma não define os métodos de seleção de pré-candidaturas, mas somente serve para 
cumprir as disposições de cada partido político por meio de seus estatutos. Assim mesmo, aprecia omissões na paridade de candidaturas para as prefeituras e no que diz respeito à direção de partidos políticos e aos órgãos administrativos do INE e OPLE.

\section{Considerações Finais}

Os comícios de 2006 no México, que impulsionaram o resultado mais apertado na história das eleições presidenciais mexicanas, se converteram em uma evidência suficientemente forte para gerar as reformas que modificaram estruturalmente a legislação eleitoral do país, ainda que muitas dessas iniciativas tivessem que esperar até 2013. Em suma, a Reforma Político-Eleitoral fomentada pelo atual governo do presidente titular Enrique Peña Nieto, pode ser recapitulada por meio de suas principais conjunturas:

1. Criação do Instituto Nacional Eleitoral - O INE foi um redesenho do IFE, mas com uma tendência forte marcada à centralização e que, ademais, devido a tantas atribuições, pode causar ao órgão um desempenho deficiente. As novas competências do INE também deslegitimam os OPLE e podem estimular o conflito pré-eleitoral. Uma das críticas pertinentes ao INE é que a competência atribuída outorga ao órgão o direito de designar e remover os Conselheiros dos OPLE, promovendo, dessa forma, uma politização do INE, e estimulando pressões quanto à nomeação dos conselheiros das entidades federativas. O método de seleção dos conselheiros federais é uma decisão política e a seleção dos conselheiros locais não aponta a uma prática que respeita a homologação e a meritocracia.

2. Reeleição - A reeleição rompe com 80 anos de resistência de um partido político que foi fundado com base no princípio de não reeleição. Ainda que a reeleição crie vínculos entre representantes e representados, a realidade é que o modelo adotado condiciona o candidato à fidelidade partidária, o que também acaba por obrigá -lo a prestar contas e preocupar-se mais com o seu partido do que com os eleitores que são representados por ele. Esse mesmo modelo é prejudicial ainda no que se refere à instauração da "renovação de mandato", o que acaba deixando o eleitor sem ferramentas para qualificação do seu representante, especialmente no que diz respeito aos legisladores "amadores". Não deixa claro que tipo de profissionalização busca seus legisladores e deixa de fora importantes 
requisitos como a escolaridade e a competência, dando espaço apenas para a popularidade do candidato. Uma das maiores debilidades está relacionada à ausência de uma cláusula que torne nula a possibilidade de que um candidato possa mudar de um posto federal a um estadual, ou vice-versa, o que acaba por permitir a um político permanecer 12 anos em um posto e, depois, mais 12 anos em outro cargo legislativo. Isso gera, suscetivelmente, um "distanciamento nocivo das elites no poder" e limita o fortalecimento da democracia.

3. Cláusula de Barreira - Em teoria, evita a fragmentação do sistema político e responde a demanda popular do aumento dos percentuais mínimos de registro para os partidos políticos, além da diminuição dos gastos eleitorais. No entanto, afetará diretamente as candidaturas de eleitores independentes e limitará a representação das minorias, sobretudo em um nível estadual onde não existe o multipartidarismo, além de que pode levar, de fato, a desaparição dos partidos de esquerda.

4. Candidaturas Independentes - Poderia abrir novas oportunidades de participação. No entanto, as normas são bastante complicadas, especificamente no que diz respeito à coleta de assinaturas que possibilitem a candidatura do postulante independente.

5. Financiamento e Gastos de campanha - $\mathrm{O}$ aumento do financiamento, que passa de $2 \%$ a $3 \%$, representa algo mínimo no que se refere ao alto preço e manutenção da democracia mexicana. Já em relação ao tema da anulação de uma candidatura devido ao excesso de gastos de campanha, este seria um passo importante para evitar algum tipo de ilegalidade nas eleições. O problema é que essa anulação só tem validez em casos de violações que sejam determinantes para a derrota do segundo colocado nas pesquisas, com uma diferença muito pequena entre o ganhador e o perdedor. Tal fator, por si só, pode tornar inoperante esse ponto específico da reforma.

6. Espaços de Rádio e Televisão - Foi uma das medidas mais racionais, tanto pelo preço e custo quanto pelo uso que os políticos e candidatos podem fazer dessa lei. A única atenção em relação a essa normativa será quanto a influência que pode ser realizada pelos meios de comunicação em favorecimento de um ou outro candidato; pois, mesmo que já exista o chamado fenômeno do pluralismo midiático, ainda há empresas hegemônicas que controlam e influenciam grande parte do eleitorado, podendo, dessa forma, definir os processos eleitorais. É importante aclarar que essa reforma, 
no tocante aos meios de comunicação, não regulamenta o conteúdo destes espaços, passando essa responsabilidade, ou seja, a de gerar propostas e conteúdos interessantes, aos partidos e aos candidatos.

7. Governos de coalizão - Essa talvez seja a medida menos acertada de todos os pontos definidos pela nova reforma eleitoral, já que teoricamente o termo coalizão não seria uma definição acertada dentro do sistema mexicano. Nesse sentido, o mais acertado seria uma reforma que profissionalize os políticos mexicanos e que não tomasse apenas o tempo permanecido no poder como requisito para tal profissionalização. A formação acadêmica e a escolaridade deveriam ser pontos importantes a serem incentivados dentro dessa nova reforma, mas infelizmente não são.

8. Paridade de Gênero - A paridade de gênero parecia ser uma medida que ninguém reclamava, pois em 2007 já se havia alterado a paridade das candidaturas para $40 \%$. No entanto, apesar de ser uma boa medida, o que falta agora é que a lei não se torne apenas uma teoria que não seja aplicada à prática e que ela sirva para que o sistema eleitoral mexicano caminhe em direção a uma cultura de igualdade, onde mulheres logrem posicionar-se cada vez mais em cargos de extrema relevância política.

\section{Referências}

ALARCÓN, V. (2013). Situación y tendencias metodológicas para el estudio del presidencialismo en América Latina y México. Seminario de Investigación del Doctorado de Procesos Políticos Contemporáneos de la Universidad de Salamanca, España.

AYALA, A. A. (1976). El día que perdió el PRI. México, DF: Contenido.

AZIS, A. (1999). Organismos electorales en México: del control a la autonomía. In: MOCTEZUMA, G. (Coord.) Derecho y legislación electoral. México: Porrúa.

BASTIDA, F. (2003). Concentración de medios y pluralismo. In: CARPIZO, J. et. al (Coords.). DD HH y derecho a la información, México: Ed. IIJ-UNAM-Porrúa.

BECERRA, J.; MIRANDA, A. (2010). El sistema interamericano de protección de los derechos humanos: especial referencia caso Castañeda vs México. Revista Sufragio: TrieJAL, vol. 3, n. 4, p. 96-108.

CARBONELL, M. (2007). Las elecciones del 2006: propuestas para una reforma electoral. Apuntes Electorales: Revista del IEEM, vol. 5, n. 26, p. 105-120.

CÓRDOVA, L. (2011). Financiamiento de Partidos en México. In: ZOVATTO, D. et al. (Coords.). Financiamiento de Partidos en América Latina. Estocolmo: IDEA. p. 349-66. 
CORONA, L. (2013). Calificación de Elecciones: elección presidencial de 2012 en México. In: MYERS, A. et al. (Coords.). Democracia y Elecciones, Salamanca: Ratio Legis.

DE ANDREA, F. (2002) Reelección legislativa consecutiva: una iniciativa de reforma riesgosa. Boletín Mexicano de Derecho Comparado, IIJ-UNAM, N 103 , Enero-Abril.

DWORAK, F. (2003). ¿Cómo sería el Congreso con reelección? Prospectiva del posible efecto del restablecimiento de la carrera parlamentaria en México. México: FCE.

ELIZONDO, M. (2012). La contribución del IFE en el desarrollo democrático de México. Revista SUFRAGIO: TrieJAL, n. 8, p. 13-19.

FARÍAS, L. (1995) Organismos electorales en 1994. In: ALVARADO et al. (Coords.). La voz de los votos: las elecciones de 1994. México: FLACSO-Porrúa.

GARCÍA, S. (2011). Reformas electorales federales en México. Redalyc, n. 166, p. 79-91.

GONZÁLEZ, M. (2009). Candidaturas independientes. Revista Sufragio: TrieJAL, n. 4, p. 43-58.

MAINWARING, S.; SHUGART, M. (1997). Juan Linz, presidentialism, and democracy: a critical appraisal. New York: Comparative Politics, p. 449-471.

MIRANDA, A. (2013). Derecho Electoral Mexicano. In: MYERS, A. et al. (Coords.). Democracia y Elecciones. Salamanca: Ratio Legis.

MIRANDA, A. (2014). La Reforma Político-Electoral en México. In: MYERS GALLARDO, A. et al. (Coords.): Estudios sobre Democracia, Estado de Derecho y Gobernanza Global. UNAM, USAL, ICADEP. Salamanca: Ratio Legis. p. 17-23.

MYERS-GALLARDO, A. (2012). Derrotas Electorales y estrategias de competencia partidista: El PRI en México. In: MYERS, A.; MARTÍNEZ, G. (Coords.). Nociones sobre Democracia y Buen Gobierno. Salamanca: Ratio Legis, p. 99-134.

MYERS-GALLARDO, A.; FAJURI, S. (2012). Derrotas Electorales, Dinámica de la Política y Estado de Derecho: El caso mexicano. Revista Sufragio: TrieJAL, n. 9, p. 142-161.

MYERS-GALLARDO, A.; FAJURI, S. (2013). El sistema de Financiamiento Electoral en España y México; evolución, vigencia y mecanismos de erradicación del fenómeno de la corrupción política. Revista Sufragio, TrieJAL, n. 10, p. 144-168.

NOHLEN, D. (1999). Sistema de gobierno, sistema electoral y sistema de partidos políticos. México: TRIPJF, IFE, Fundación Friedrich Naumann.

PRZEWORSKI, A. et al. (1999). Elections and Representation. New York: Cambridge U. Press.

SARTORI, G. (2003). Ingeniería constitucional comparada: una investigación de estructuras, incentivos y resultados. México: FCE.

WOLDENBERG, J. (1990). Elecciones y Legislación en México. REIS, 50/90, p. 27-42. 
ZARKIN, J. (2013). Revocación de mandato y su efecto como mecanismo de disuasión. Un estudio de la política económica de los estados en USA. México: ITAM.

\section{Outras fontes:}

Instituto Nacional Electoral: http://www.ine.org.mx/

Pacto Por México http://pactopormexico.org/acuerdos/\#gobernabilidad-democratica Gaceta Parlamentaria (México): http://gaceta.diputados.gob.mx

International Institute for Democracy and Electoral Assistance. www.quotaproject.org Yo soy 132: http://www.yosoy132media.org/

Pacto por México: http://pactopormexico.org 